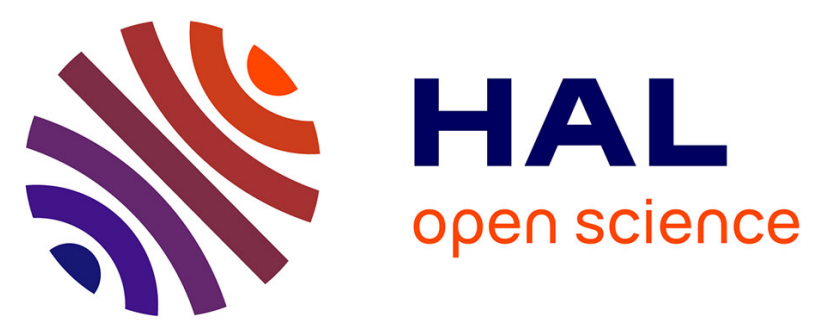

\title{
Enhanced engraftment and repairing ability of human adipose-derived stem cells, conveyed by pharmacologically active microcarriers continuously releasing HGF and IGF-1, in healing myocardial infarction in rats
}

\author{
Monia Savi, Leonardo Bocchi, Emanuela Fiumana, Jean-Pierre Karam, \\ Caterina Frati, Francesca Bonafé, Stefano Cavalli, Paolo Morselli, Carlo \\ Guarnieri, Claudio Caldarera, et al.
}

\section{To cite this version:}

Monia Savi, Leonardo Bocchi, Emanuela Fiumana, Jean-Pierre Karam, Caterina Frati, et al.. Enhanced engraftment and repairing ability of human adipose-derived stem cells, conveyed by pharmacologically active microcarriers continuously releasing HGF and IGF-1, in healing myocardial infarction in rats. Journal of Biomedical Materials Research Part A, 2015, pp.3012-3025. 10.1002/jbm.a.35442 . hal-01392450

\author{
HAL Id: hal-01392450 \\ https://hal.science/hal-01392450
}

Submitted on 7 Sep 2021

HAL is a multi-disciplinary open access archive for the deposit and dissemination of scientific research documents, whether they are published or not. The documents may come from teaching and research institutions in France or abroad, or from public or private research centers.
L'archive ouverte pluridisciplinaire HAL, est destinée au dépôt et à la diffusion de documents scientifiques de niveau recherche, publiés ou non, émanant des établissements d'enseignement et de recherche français ou étrangers, des laboratoires publics ou privés. 


\title{
Enhanced engraftment and repairing ability of human adipose-derived stem cells, conveyed by pharmacologically active microcarriers continuously releasing HGF and IGF-1, in healing myocardial infarction in rats
}

\author{
Monia Savi, ${ }^{1}$ Leonardo Bocchi, ${ }^{1}$ * Emanuela Fiumana, ${ }^{2,3}$ Jean-Pierre Karam, ${ }^{3,4,5}$ \\ Caterina Frati, ${ }^{6}$ Francesca Bonafé, ${ }^{2,3}$ Stefano Cavalli, ${ }^{6}$ Paolo G. Morselli, ${ }^{7}$ Carlo Guarnieri, ${ }^{2,3}$ \\ Claudio M. Caldarera, ${ }^{2,3}$ Claudio Muscari, ${ }^{2,3}$ Claudia N. Montero-Menei, ${ }^{4,5}$ Donatella Stilli,, \\ Federico Quaini, ${ }^{2,6}$ Ezio Musso ${ }^{1,2}$ \\ ${ }^{1}$ Department of Life Sciences, University of Parma, Parco Area delle Scienze 11/A, 43124 Parma, Italy \\ ${ }^{2}$ National Institute for Cardiovascular Research, Bologna, Italy \\ ${ }^{3}$ Department of Biomedical and Neuromotor Sciences, University of Bologna, Via Irnerio 48, 40126 Bologna, Italy \\ ${ }^{4}$ UMR S-1066 F-49933, LUNAM University, Angers, France \\ 5INSERM U1066, MINT “Micro Et Nanomédecines Biomimétiques "F-49933, Angers, France \\ ${ }^{6}$ Department of Clinical and Experimental Medicine, University of Parma, Via A. Gramsci 14, 43126 Parma, Italy \\ ${ }^{7}$ Department of Specialist, Diagnostic and Experimental Medicine, University of Bologna, Bologna, Italy
}

\begin{abstract}
One of the main cause of ineffective cell therapy in repairing the damaged heart is the poor yield of grafted cells. To overcome this drawback, rats with 4-week-old myocardial infarction (MI) were injected in the border zone with human adipose-derived stem cells (ADSCs) conveyed by poly(lactic-coglycolic acid) microcarriers (PAMs) releasing hepatocyte growth factor (HGF) and insulin-like growth factor-1 (IGF-1) (GFsPAMs). According to treatments, animals were subdivided into different groups: MI_ADSC, MI_ADSC/PAM, MI_GFsPAM, MI_ADSC/ GFsPAM, and untreated MI_V. Two weeks after injection, a 31\% increase in ADSC engraftment was observed in MI_ADSC/PAM compared with MI_ADSC $(p<0.05)$. A further ADSC retention was obtained in MI_ADSC/GFsPAM with respect to MI_ADSC $(106 \%, p<0.05)$ and MI_ADSC/PAM $(57 \%, p<0.05)$. A $130 \%$ higher density of blood vessels of medium size was present in
\end{abstract}

MI_ADSC/GFsPAM compared with MI_ADSC $(p<0.01)$. MI_ADSC/GFsPAM also improved, albeit slightly, left ventricular remodeling and hemodynamics with respect to the other groups. Notably, ADSCs and/or PAMs, with or without HGF/IGF1, trended to induce arrhythmias in electrically driven, Langendorff-perfused, hearts of all groups. Thus, PAMs releasing HGF/IGF-1 markedly increase ADSC engraftment 2 weeks after injection and stimulate healing in chronically infarcted myocardium, but attention should be paid to potentially negative electrophysiological consequences. (C) 2015 Wiley Periodicals, Inc. J Biomed Mater Res Part A: 00A:000-000, 2015.

Key Words: pharmacologically active microcarrier, adiposederived stem cell, hepatocyte growth factor, insulin-like growth factor 1, myocardial infarction, arrhythmia

\section{INTRODUCTION}

Various stem cell or progenitor cell populations have been tested to repair the damaged heart. Yet, no general consen- sus has been reached so far on the ability of cell therapy to regenerate the infarcted myocardium. Additionally, the efficiency of the treatment appeared to be limited by

Additional Supporting Information may be found in the online version of this article.

*These authors equally contributed equally to this work.

Correspondence to: C. Muscari; e-mail: claudio.muscari@unibo.it (or) F. Quaini; e-mail: federico.quaini@unipr.it (or) D. Stilli; e-mail: donatella. stilli@unipr.it

Contract grant sponsor: Compagnia di San Paolo, Turin, Italy (Project: “Rigenerazione del miocardio infartuato mediante stimolazione di cellule staminali indotta da microsfere biomimetiche")

Contract grant sponsor: Fondazione Dr. Carlo Fornasini

Contract grant sponsor: Poggio Renatico (FE), Italy

Contract grant sponsor: European Grant FP7-NMP-2007 ; contract grant number: 214539 (BIOSCENT - BIOactive highly porous and injectable Scaffolds controlling stem cell recruitment, proliferation and differentiation and enabling angiogenesis for Cardiovascular ENgineered Tissues) 
insufficient cell retention and survival, as up to $90 \%$ of the transplanted cells may die within $24 \mathrm{~h}$ after injection in the infarcted heart. ${ }^{1-3}$ To improve these outcomes, attention has been paid to several factors such as tailoring of cell type and optimization of engraftment techniques.

Adipose-derived stem cells (ADSCs) own advantageous properties compared to other stem cells as they can be easily harvested with high yield, expanded, and safely transplanted to an autologous or allogeneic host, displaying the ability to differentiate into various cell types, including cardiomyocytes. $^{4-7}$

Cell engraftment might be enhanced using microspheres formed by biodegradable and noncytotoxic poly(lactic-coglycolic acid) (PLGA), which exhibit therapeutic potential by releasing bioactive factors and enabling interaction between cells conveyed on their surface and those populating the host tissue. ${ }^{8}$ These microspheres, covered with molecules of the extracellular matrix (ECM) and defined pharmacologically active microcarriers (PAMs), ${ }^{8}$ have been shown to preserve survival and foster differentiation of the transported cells until the complete degradation of the carrier. ${ }^{9-13}$

In recent experiments, growth factors and other proteins were encapsulated under a nanosolid state within the PLGA polymer to preserve their structure and integrity, allowing a better and prolonged release profile and the maintenance of their biological activity. ${ }^{14,15}$ Concurrently, factors contained in these polymeric particles not only are more protected from the molecular changes induced by the environment but can also be gradually released upon a prolonged period that is likely necessary to facilitate the repair of damaged tissue.

In this study, we developed PAMs which possess a biomimetic surface composed of fibronectin-like sequences (FN) as bioadhesive and natural ECM component for ADSCs and are capable to release hepatocyte growth factor (HGF) and insulin-like growth factor-1 (IGF-1) in a sustained manner. ${ }^{16}$ Among growth factors used in myocardial repair, we chose HGF and IGF-1 because they have been validated for cardiac tissue engineering especially as prosurvival and angiogenic agents. ${ }^{17-21}$ HGF + IGF-1 were also reported to promote cardiac regeneration when injected as a bolus, in the same model of chronic myocardial infarction (MI) adopted in the present work. $^{22}$ To our knowledge, HGF and IGF-1 have never been used for cell therapy in combination with ADSCs.

Here, we tested the hypothesis that ADSC engraftment can be increased through intra-myocardial delivery of cells transported by FN-covered PAMs and that the sustained release of HGF and IGF-1 could improve the yield of cell transplantation in a rat model of healing MI. We also investigated the effects of the treatment on neovascularization of the infarcted region as well as left ventricle (LV) hemodynamics, electrophysiology, and remodeling.

\section{MATERIALS AND METHODS}

The study was carried out in strict accordance with the recommendations in the Guide for the Care and Use of Laboratory Animals of the National Institute of Health (NIH
Publication \#85-23 Rev. 1985). The protocol conforms to the National Ethical Guidelines of the Italian Ministry of Health (Permit number: 41/2009-B). For all surgical procedures performed in clinical settings, the principles outlined in the Declaration of Helsinki were followed and an authorization was prior subscribed by the enrolled patients.

\section{Materials}

All materials were purchased from Sigma-Aldrich (St. Louis, MO), unless otherwise stated.

\section{PAM formulation and GF release profile}

PLGA-microspheres of an average diameter of $60 \mu \mathrm{m}$ were prepared using a previously described emulsion solvent extraction-evaporation process. ${ }^{14}$ Given that accurate delivery of therapeutic proteins at physiological levels requires low encapsulation loading, in accordance with our previous reports, ${ }^{12,13}$ the total protein loading was $0.6 \% \mathrm{w} / \mathrm{w}$ of the amount of microspheres, that is, $0.1 \%$ HGF or $0.1 \%$ IGF-1 (Peprotech, Neuilly sur Seine, France), and 0.5\% human serum albumin (HSA). Concurrently, we formulated two different kinds of PAMs, depending on HGF or IGF-1 encapsulation. As a first step, $\mathrm{NaCl}$ and glycofurol were used to precipitate the proteins separately. ${ }^{14}$ For HGF and IGF-1 (50 $\mu$ g each), a $\mathrm{NaCl}$ solution at 0.5 and $2 M$, respectively, was used. This solution, maintained at $4{ }^{\circ} \mathrm{C}$, was added to a poloxamer 188 excipient (poloxamer/ $\mathrm{NaCl}$ ratio $1 / 1 \mathrm{v} / \mathrm{v}$ ) in an additive to protein ratio of $20: 1$ and further mixed to glycofurol to form a $1 \mathrm{~mL}$ suspension. The same procedure was used for $250 \mu \mathrm{g}$ of $\mathrm{HSA}$ with a $\mathrm{NaCl}$ solution at $0.3 \mathrm{M}$. The nanoprecipitates were then carefully dispersed in the organic solution containing $50 \mathrm{mg}$ PLGA, water was added, and the resulting $\mathrm{o} / \mathrm{w}$ emulsion formed the imprint of the microparticles, which were filtered after organic solvent extraction. ${ }^{23}$ Unloaded microparticles were prepared in the same manner without adding the protein. PLGA microspheres were coated with FN (Sigma, Saint-Quentin Fallavier, France) combined with poly-D-lysine molecule (PDL; Sigma, France) to obtain PAMs. ${ }^{12,13}$ Briefly, microspheres were suspended in Dulbecco's phosphate buffered saline (DPBS), sonicated until full dispersion and were then incubated with $6 \mu \mathrm{g} / \mathrm{mL}$ PDL by continuous stirring at $15 \mathrm{rpm}$ for $90 \mathrm{~min}$. The microspheres were formulated in aseptic conditions and were thereafter incubated for $10 \mathrm{~min}$ with antibiotics after the coating step. Each tube was covered with sigmacote ${ }^{\circledR}$ (Sigma, France) to prevent product loss on the tube walls. PAMs were then freeze-dried and stored at $4^{\circ} \mathrm{C}$ for the experiments or immediately used for release kinetics studies.

GF encapsulation yield was determined by measuring the entrapped proteins via enzyme-linked immunosorbent assay (ELISA) kits for HGF and IGF-1 (R\&D systems, Lille Cedex, France).

The in vitro release profile of each GF from PAMs was followed for 3 weeks and determined by adding $250 \mu \mathrm{L}$ of phosphate buffered saline (PBS), pH 7.4, containing 1\% w/v bovine serum albumin (BSA), to $2.5 \mathrm{mg}$ of microspheres into Eppendorf tubes. The tubes were closed and incubated in a shaking water bath $\left(37^{\circ} \mathrm{C}, 125 \mathrm{rpm}\right)$. At selected times, 
the tubes were centrifuged for $5 \mathrm{~min}$ at 3,000 rpm and 250 $\mu \mathrm{L}$ of the supernatant were collected for analysis and replaced by fresh buffer. The amount of each aliquot of released GF was evaluated by ELISA) and checked for its bioactivity by performing a proliferation assay (Alamar Blue assay) with appropriate cell types, that is, human umbilical vein endothelial cells (HUVECs) for HGF and NIH3T3 fibroblasts for IGF-1.

Values of encapsulation yield, kinetic profile, and bioactivity of the released GFs have been previously reported. ${ }^{16}$ Briefly, 95 and 99\% yield of encapsulation was achieved for HGF and IGF-1, respectively. An initial burst release was similar for both GFs corresponding to about $5 \mathrm{ng} \mathrm{GF} / \mathrm{mg}$ $\mathrm{PAM} /$ day in the first week. A plateau was reached by HGF at the beginning of the third week whereas IGF-1 did not, probably due to its smaller size and better stability. For $1 \mathrm{mg}$ PAMs a cumulative release of $344 \mathrm{ng} / \mathrm{mL}$ of $\mathrm{HGF}$ and $320 \mathrm{ng} / \mathrm{mL}$ of IGF-1 (25-30\% of total entrapped GF) was obtained upon 3 weeks and the bioactivity for both GFs ranged from 90 to $100 \%$.

\section{Liposuction procedure and ADSC isolation}

The lipoaspirates were collected from the subcutaneous adipose tissue of the abdominal region of subjects of both genders ranging in age from 18 to 60 years. A $60 \mathrm{~mL}$ syringe was connected to a $4 \mathrm{~mm}$ diameter cannula and a vacuum pressure of $450-550 \mathrm{mmHg}$ was created into the subcutaneous tissue in order to collect about $50 \mathrm{~mL}$ of adipose tissue. The raw lipoaspirate was processed to achieve cell isolation in accordance with the method of Zuk et al. ${ }^{24}$

For ADSC expansion, $2 \times 10^{6}$ cells were seeded in $75 \mathrm{~cm}^{2}$ flask containing $20 \mathrm{~mL}$ of complete medium for $24-$ $48 \mathrm{~h}$. The plates were then washed extensively with PBS to remove residual nonadherent and red blood cells. ADSCs were maintained in complete medium and allowed to reach confluence, then were gently detached by trypsin digestion (passage $0, \mathrm{P} 0$ ) and split in three plastic dishes of $10 \mathrm{~cm}$ diameter each. The cell culture medium was changed twice a week until P2.

The ADSCs used for both in vitro cell characterization and evaluation of PAM adhesion were isolated from different subjects, while those injected in infarcted rat hearts were obtained from only one male patient in order to use ADSCs with the same phenotypic features and track them within the rat cardiac tissue by fluorescence in situ hybridization (FISH) analysis of human specific chromosome $\mathrm{X}$ and $\mathrm{Y}$.

The surface markers of the stromal vascular fraction (SVF) adherent cells at P2 were investigated by flow cytometry analysis using an Epics Elite XL-MCL flow cytometer (Beckman Coulter, Fullerton, CA) equipped with a 15-mW argon ion laser tuned to $488 \mathrm{~nm}$. The following primary mouse monoclonal antibodies against human external cell surface were used: CD31 1:50 (Dako, Milan, Italy), CD34 1:80 (Dako), CD44 1:50 (BD Pharmingen, Milan, Italy), CD90 1:100 (BD Pharmingen), CD133 1:100 (Miltenyi Biotec, Calderara di Reno, Italy), c-kit 1:200 (Dako), Stro-1 1:100 (R\&D, Milan, Italy), mononuclear phagocyte factor (MPF) 1:100 (BD Pharmingen), and $\alpha-$ smooth muscle actin
( $\alpha$-SMA) 1:100 (Chemicon/Millipore, Milan, Italy). The antibodies were diluted in blocking buffer (PBS, 1\% BSA, 0.1\% tween 20) for $1 \mathrm{~h}$ at room temperature and washed three times in PBS. The secondary Cy3-conjugated polyclonal antimouse antibody (Sigma, Milan, Italy) was diluted 1:2000 in the blocking buffer and washed three times in PBS. Negative controls were obtained with the Cy3-conjugated secondary antibody. Cy3 red fluorescence was collected at $575 \mathrm{~nm}$.

\section{Preparation of PAM/ADSC suspension}

Aliquots of $0.5 \mathrm{mg}$ of freeze-dried PAMs were incubated with $0.3 \mathrm{~mL}$ of culture medium for $15 \mathrm{~min}$ at room temperature. PAM suspensions were vortexed, put in an ultrasound bath for $30 \mathrm{~s}$, and vortexed again. Each suspension of $0.5 \mathrm{mg}$ PAM was poured in a well of a 12 ultra-low attachment multiwells (Corning-Costar, NY). Then, $6.5 \times 10^{3}, 2.5$ $\times 10^{4}, 5 \times 10^{4}$, and $1 \times 10^{5}$ ADSCs stained in the nucleus with 4,6-diamidino-2-phenylindole (DAPI) were suspended in complete medium and added into each well in triplicate. The ADSCs were allowed to adhere to PAMs for 3 and $24 \mathrm{~h}$, then the upper $0.5 \mathrm{~mL}$ supernatant was discarded and the remaining PAM/ADSC complexes were observed by lightfluorescence mixed microscopy (IX50 Olympus, Olympus Italia, Segrate, Italy).

To detect homing of the injected cells into murine hearts, ADSCs were processed using the CellTracker CM-DiI (Invitrogen, Turin, Italy), a di-alkyl-indocarbocyanine derivative containing a thiol-reactive chloromethyl moiety (CM) that allows the dye to covalently bind to cellular thiols. Thus, unlike other membrane stains, this label is well retained in the cells throughout several mitotic divisions and cell to cell contact does not allow dye diffusion. ADSCs were incubated in 1-2 $\mu \mathrm{M}$ working solution for $15 \mathrm{~min}$ at $37^{\circ} \mathrm{C}$, and then for an additional $15 \mathrm{~min}$ at $4^{\circ} \mathrm{C}$. Incubation at this lower temperature appears to allow the dye to label the plasma membrane but slows down endocytosis, thus reducing dye localization into cytoplasmic vesicles. After labeling, cells were washed with PBS, resuspended in fresh medium, and used for experiments.

The complexes of $0.5 \mathrm{mg}$ PAMs $(0.25 \mathrm{mg}$ HGF$\mathrm{PAM}+0.25 \mathrm{mg}$ IGF-1-PAM) and $1 \times 10^{5}$ Dil-ADSCs, generated after $3 \mathrm{~h}$ of incubation in $1.0 \mathrm{~mL}$ complete medium at room temperature, were centrifuged at $500 \mathrm{~g}$ for $2 \mathrm{~min}$, and resuspended with $80 \mu \mathrm{L}$ of the injection solution containing 0.094\% sodium carboxymethyl-cellulose, $0.37 \%$ mannitol, $0.094 \%$ polysorbate, and serum-free medium.

\section{Animal population and outline of the in vivo experimental protocol}

Eighty-five male Wistar rats, aged 12-14 weeks and weighing 300-350 g, were subjected either to myocardial infarction (MI group) or sham operation (SHAM group). Four weeks later, all animals were randomly selected to receive specific treatments as indicated below and subdivided in corresponding subgroups. Eleven rats died in the perioperative periods leaving a total of 74 rats.

The in vivo experimental protocol consisted of two phases: a preliminary phase in which the cardiac 
biocompatibility of empty PAMs was evaluated (phase one) and a second phase in which the hemodynamic, electrophysiological, and histoanatomical effects of PAM/ADSC complexes were assessed (phase two).

\section{Procedures for induction of MI and local injection of specific treatments}

Rats were anesthetized with ketamine chloride $40 \mathrm{mg} / \mathrm{kg}$ i.p. (Imalgene, Merial, Milan, Italy) plus medetomidine hydrochloride $0.15 \mathrm{mg} / \mathrm{kg}$ i.p. (Domitor, Pfizer Italia S.r.l., Latina, Italy), intubated with a properly modified 16-gauge needle, and mechanically ventilated (Rodent ventilator UB 7025, Ugo Basile, Comerio, Italy). With the aid of a dissecting microscope, a thoracotomy via the third-left intercostal space was performed and a 5-0 silk suture was passed with a tapered needle under the left anterior descending coronary artery, 2-3 $\mathrm{mm}$ from the edge of the left auricle, and tied securely. The development of a pale color in the distal myocardium on ligature, as noted by visual inspection, was taken as an index of the successful performance of coronary occlusion. The chest was then closed in layers, and a small catheter was introduced in the thorax to evacuate air and fluids. The rats were given atipamezole hydrochloride $0.15 \mathrm{mg} / \mathrm{kg}$ i.m. (Antisedan, Pfizer Italia), removed from the ventilator, kept warm with infrared lamp radiation, and eventually individually housed. Antibiotic therapy was given during the subsequent 3 days (gentamicin sulphate $10 \mathrm{mg} /$ kg i.m.; Aagent, Fatro, Milan, Italy). Sham-operated rats were treated similarly, except that the ligature around the coronary artery was not tied.

Four weeks after coronary ligature, left lateral thoracotomy was repeated in all animals under anesthesia and mechanical ventilation, as described above. In accordance with a well established procedure long been adopted by our group, $^{20,22}$ four intramyocardial injections $(20 \mu \mathrm{L}$ each) of the selected treatment were performed at opposite sides of the infarct border zone using a Hamilton syringe (26-G needle). To ensure the correct location of the syringe needle in the subepicardial region of the LV wall, surgical microscopy (magnification $150 \times$ ) was used. In addition, the accuracy of injection was preliminarily assessed via the adjunct to the syringe solution of Rhodamine particles (see below) that could be visualized by both inspection and under fluorescence microscopy.

\section{Preliminary study of PAM biocompatibility (phase one of the experimental protocol)}

Thirty-six rats, four weeks after MI $(n=18)$ or sham operation $(n=18)$, were treated with $20 \mu \mathrm{L}$ of $0.5 \mathrm{mg}$ empty PAMs (MI_PAM, $n=9$; SHAM_PAM, $n=9$ ) or $20 \mu \mathrm{L}$ of vehicle (MI_V, $n=9$; SHAM_V, $n=9$ ). Vehicle was normal saline $(0.9 \% \mathrm{w} / \mathrm{v}$ of $\mathrm{NaCl})$. Rhodamine spheres were added to the vehicle solution $(5 \% \mathrm{v} / \mathrm{v})$ to mark the point of injection. One week after treatment, three rats of each group were anaesthetized with ketamine+medetomidine and the hearts were arrested in diastole by i.m. injection of $5 \mathrm{~mL} \mathrm{CdCl} 2$ solution $(100 \mathrm{mM})$. The myocardial vasculature was perfused at physiological pressure with heparinized PBS- solution, followed by perfusion with $10 \%$ formalin solution. The heart was then excised and placed in formalin solution (10\%) for 24 hours. Subsequently, five $\mu$ m-thick sections of paraffin inclusions were obtained to evaluate the fibrotic damage and the presence of inflammatory foci. The number and size of foci of reparative fibrosis were measured by morphometric analysis. All the procedures were repeated for an additional three rats of each group 2 weeks after treatment and for the remaining animals after 4 weeks.

\section{Assessment of the morphofunctional effects of PAM/ ADSC injection (phase two of the experimental protocol)}

Thirty-three rats with 4-week-old MI were subjected to intramyocardial injection of ADSCs (MI_ADSC, $n=8$ ), ADSCs plus PAMs (MI_ADSC/PAM, $n=7$ ), GF-releasing PAMs (MI_GFsPAM, $n=6$ ), ADSCs plus GF-releasing PAMs (MI_ADSC/GFsPAM, $n=6$ ) or vehicle (MI_V, $n=6$ ). Five additional rats were sham operated (SHAM_V). Two weeks after treatment, hemodynamic parameters were invasively determined in Millar conductance catheter studies and inducibility of ventricular arrhythmias was assessed in Langendorff-perfused hearts. Eventually, the hearts were subjected to anatomical, morphometric, and immunohistochemical analyses.

Hemodynamic measurements. The rats were anaesthetized as described above and invasive hemodynamic data were recorded with a microtip pressure transducer catheter (Millar SPC-320, Millar Instruments, Houston, TX, USA) inserted into the right carotid artery and connected to a recording system (Power Laboratory ML 845/4 channels, 2Biological Instruments, Besozzo, Italy). The catheter was then advanced into the LV to measure the following parameters: (1) left ventricular systolic pressure (LVSP), (2) LV end-diastolic pressure (LVEDP), (3) the peak rate of rise and decline of $\mathrm{LV}$ pressure $( \pm \mathrm{dP} / \mathrm{dt})$, taken as indexes of ventricular mechanical efficiency, (4) isovolumic contraction time (IVCT: duration of isovolumic contraction), (5) LV relaxation time (LVRT), computed from $-\mathrm{dP} / \mathrm{dt}$ to $5 \mathrm{mmHg}$ above LVEDP, and (6) ejection time (EJT), approximated as the time interval between aortic valve opening and $-\mathrm{dP} / \mathrm{dt}$ (software package AcqKnowledge 3.9; Biopac Systems, Goleta, CA).

Inducibility of ventricular arrhythmias. The heart and $5 \mathrm{~mm}$ of attached proximal aorta were rapidly excised through median sternotomy, placed in an ice-cold $\left(4^{\circ} \mathrm{C}\right)$ physiological saline solution to induce cardiac arrest and mounted on a Langendorff isolated heart perfusion apparatus by the aorta. Perfusion fluid was a modified Tyrode's solution containing (in $\mathrm{m} M$ ): $\mathrm{NaCl} 140.0, \mathrm{KCl} 5.4, \mathrm{MgCl}_{2}$ 1.0, $\mathrm{CaCl}_{2}$ 1.0, HEPES 24.0, and glucose 11.0. The solution was aerated with $100 \%$ oxygen, temperature was regulated at $37^{\circ} \mathrm{C}$, and the $\mathrm{pH}$ was adjusted to 7.4 with $\mathrm{NaOH}$ as necessary. Coronary flow was maintained at $10 \mathrm{~mL} / \mathrm{min}$ with a peristaltic pump (Masterflex Easy-Load II, model 77202-50, Cole-Palmer, Vernon Hills, IL) via a cannula in the aorta. A flexible, $6 \times 6$ 
microelectrode array (EcoFlexMEA36, Multi Channel Systems) was laid down on the LV surface for unipolar electrogram (EG) recording (gain 1000, bandwith $0.1-500 \mathrm{~Hz}$, sampling rate $1,000 \mathrm{~Hz}$ ). After a period of stabilization (5-10 min) at sinus rhythm, inducibility of ventricular arrhythmias was assessed by programmed electrical stimulation (PES) and rapid ventricular pacing (RVP). For both approaches, appropriate sequences of square-wave electrical impulses were delivered to the pulmonary cone area through electrically insulated platinum wires inserted in the ventricular wall and connected to a general purpose stimulus generator (STG4002, Multi Channel Systems, Reutlingen, Germany). The driving sequences were followed by $10 \mathrm{~s}$ recording at spontaneous rhythm. PES and RVP protocols are schematically described in Supporting Information Figure S1.

Arrhythmias were classified according to the Lambeth Conventions $^{25}$ and their severity quantified using a scoring system proposed by Curtis et al. ${ }^{26}$ with minor modifications. The score value was expressed by:

$$
\begin{gathered}
\left(\log _{10} \text { PVB number }\right)+2\left(\log _{10} \text { VT number }\right) \\
+2\left(\log _{10} \text { total VT duration }\right)
\end{gathered}
$$

where $\mathrm{PVB}=$ premature ventricular beat and VT $=$ ventricular tachycardia.

Anatomical parameters and morphometric analysis. The hearts of anesthetized animals were arrested in diastole, fixed and excised as described above (phase one of the experimental protocol). The right ventricle and the LV inclusive of the septum were separately weighed and the volume of the left ventricular myocardium was computed by dividing $\mathrm{LV}$ weight by the specific gravity of the tissue $(1.06 \mathrm{~g} / \mathrm{mL})$.

The major cavitary axis of the LV was measured from the aortic valve to the apex, under a stereomicroscope with a ruler calibrated exactly to $0.1 \mu \mathrm{m}$ (2Biological Instruments). Subsequently, the heart was sliced in three $1-\mathrm{mm}$ thick transversal sections, at the basal, equatorial, and apical levels of the ventricle. On the equatorial section, LV wall thickness and LV chamber diameter were morphometrically determined using a software for image analysis (Image Proplus 4.0). LV chamber volume was calculated according to the Dodge equation, which equalizes the ventricular cavity to an ellipsoid. ${ }^{27}$ Afterwards, the sections were embedded in paraffin. Five- $\mu \mathrm{m}$ thick slices were finally cut from the equatorial portion of the LV free wall for morphometric, cell tracking and immunohistochemical studies.

The infarcted portion of the ventricle was easily identifiable grossly and histologically. In MI animals, the area of the damaged tissue from the endocardial to the epicardial layer and the total area of the viable myocardium were measured in the three slices corresponding to the base, mid-region and apex indicated above, and divided by the total LV area explored (overall mean).

Immunostaining of cardiac vessels. Immunohistochemical analysis on formalin-fixed, paraffin-embedded $5 \mu \mathrm{m}$-thick tissue sections was used to reveal von Willebrand factor (vWF). After dewaxing and rehydration, the endogenous peroxidase activity was blocked with $3 \% \mathrm{H}_{2} \mathrm{O}_{2}$ for $10 \mathrm{~min}$ and the antigens retrieved in a microwave for $10 \mathrm{~min}$ at full power in $10 \mathrm{~m} M$ citrate buffer, $\mathrm{pH}$ 6.0. An antigen-antibody reaction was developed using a NovoLink Polymer Detection Kit (Novocastra, Newcastle upon Tyne, UK). Sections were incubated overnight at $4^{\circ} \mathrm{C}$ with mouse monoclonal antibodies anti-vWF (Abcam, Cambridge, UK). The sections were then incubated with NovoLinkTM Polymer for $30 \mathrm{~min}$ at RT, and subsequently with 3,30-diaminobenzidine (Novocastra). The sections were rinsed in distilled water and counterstained with Gill's haematoxylin. LM images were acquired using IX50 Olympus inverted microscope (Olympus Italia). The circular/oval structures lined by $\mathrm{vWF}^{+}$cells were identified as capillaries when their diameter was $<20 \mu \mathrm{m}$, while they were considered as arterioles, venules, or immature vessels of medium size when $>20 \mu \mathrm{m}$. The diameter of the oval vessels was calculated as the half-sum between the largest and the shortest dimension. To obtain the values of vascular density per unit area $\left(0.33 \mathrm{~mm}^{2}\right)$ both capillaries and medium-sized vessels were separately counted in six different fields of the sections showing the highest vessel density.

ADSC tracking in the infarcted heart. Five- $\mu$ m thick sections of the LV were analyzed to detect the efficiency of cell injection and homing to the infarcted myocardium.

Fluorescent images of CM-DiI stained ADSCs were digitally captured via a digital camera (Leica DFC350FX, Milan, Italy) connected to a motorized epifluorescent microscope (Leica DMI6000B) provided by a Z-stack automation system. Image analysis was performed with "LAS Advanced Fluorescence" software (Leica Microsystems). Quantification of cell homing was performed on photomicrographs covering the entire area of LV sections, to detect red fluorescent spots corresponding to pre-labeled cells adherent to PAMs.

The fractional area occupied by red fluorescence and its intensity, expressed as Integrated Optical Density, were then evaluated using a software for image analysis (Image Pro Plus 4.0). All images were acquired with precalibrated gain and exposure time. Aspecific fluorescence measurements were carried out by merging the emission signals from different excitation lengths on the same microscopic field.

ADSCs were also documented by FISH to detect human $\mathrm{X}$ and $\mathrm{Y}$ chromosomes using human specific CEP $\mathrm{X}$ alphasatellite and CEP Y satellite III DNA probes (Abbott Laboratories, Des Plaines, IL). ${ }^{28}$

\section{Statistical analysis}

The SPSS statistical package (SPSS, Chicago, IL, version 18) was used. Normal distribution of variables was checked by means of the Kolmogorov-Smirnov test. Statistics of variables included mean \pm SEM and one-way ANOVA (post-hoc analysis: Bonferroni or Games-Howell test, when appropriate). Statistical significance was set at $p<0.05$. 
TABLE I. Marker Profile of ADSCs

\begin{tabular}{lc}
\hline Superficial Markers & $\%$ of Positive ADSCs $(n=4)$ \\
\hline CD31 & $1.05 \pm 0.42$ \\
CD34 & $0.35 \pm 0.19$ \\
CD44 & $70.9 \pm 9.16$ \\
CD90 & $67.8 \pm 6.74$ \\
CD133 & $0.07 \pm 0.02$ \\
c-kit & $0.30 \pm 0.11$ \\
Stro-1 & $0.05 \pm 0.03$ \\
MPF & $1.25 \pm 0.62$ \\
$\alpha$-SMA & $30.5 \pm 15.0$ \\
\hline
\end{tabular}

Percentage of $\mathrm{ADSC}^{\text {pos }}$ cells for each surface cell marker. Values are expressed as mean \pm SEM.

\section{RESULTS}

\section{Flow cytometry characterization of ADSCs}

The flow cytometry analysis of the adherent cells derived from the SVF at P2 confirmed both their mesenchymal-like phenotype (largely positive to CD44 and CD90), and the scarcity of cells of different lineages, such as endothelial $\left(\mathrm{CD} 31^{-}\right)$, hematopoietic (CD34 ${ }^{-}, \mathrm{CD} 133^{-}$, and c-kit ${ }^{-}$), and macrophagic $\left(\mathrm{MPF}^{-}\right)$cells (Table I). Therefore, we considered that this cell population was particularly enriched in ADSCs. They were also dimly positive to $\alpha$-SMA, although we cannot exclude the presence of other $\alpha$-SMA ${ }^{+}$phenotypes, such as pericytes, ${ }^{29}$ myofibroblasts, and vascular smooth muscle cells. Moreover, ADSCs were negative to Stro-1 in accordance with several studies, although it has also been reported that they can stain positive for this marker. ${ }^{30}$

\section{In vitro ADSC/PAM complex formation}

ADSCs, ranging from $6.5 \times 10^{3}$ to $1 \times 10^{5}$, were suspended in the presence of $0.5 \mathrm{mg}$ PAMs in order to investigate their ability to adhere to the microparticle surfaces. Almost all ADSCs covered PAMs just after $3 \mathrm{~h}$, irrespective of the amount of cells used (Supporting Information Fig. S2). An increased tendency of ADSCs to bridge two or more PAMs was observed by enhancing the ADSC/PAM ratio and prolonging the time of incubation up to $24 \mathrm{~h}$ (images not shown). Therefore, ADSCs were allowed to adhere to PAMs for $3 \mathrm{~h}$ just before their injection in the cardiac wall through a 26-G needle. The procedure caused the destruction of most aggregates and the formation of a higher number of smaller ADSC/PAM complexes constituted by one PAM covered by only some ADSCs (Fig. 1).

\section{Evaluation of PAM biocompatibility: inflammatory response in the infarcted hearts injected with empty PAMs}

The analysis of the inflammatory reaction occurring within 2 weeks after PAM injection showed that it was confined to injection site at the subepicardial layer, with poor inflammatory cell infiltration, in MI_V and SHAM_V hearts [Fig. 2(AC)], while in MI_PAM and SHAM_PAM small inflammatory areas were also observed at mid-myocardial level [Fig. 2(D)].

However, 4 weeks after injection, a relevant decrease of the inflammatory response was observed in all groups, although microfoci of inflammation were still present in rats treated with PAMs. A quantitative analysis of the injured areas indicated that, two weeks after injection, the number, and dimension of the fibrotic foci with cell infiltration and little spot of myocytolysis were higher in the hearts treated with PAMs than in control hearts injected with vehicle. At the later time point ( 4 weeks after injection), the amount, and morphology of tissue damage were similar in PAM- and vehicle-injected hearts (data not shown).

\section{Effects of ADSC/PAM injection on hemodynamics}

In comparison with SHAM_V, MI_V rats exhibited a global deterioration of hemodynamic performance involving both contraction and relaxation phases, as indicated by the significant decrease in left ventricular systolic pressure (LVSP), the maximal rate of $\mathrm{LV}$ pressure rise $(+\mathrm{dP} / \mathrm{dt})$ and decline $(-\mathrm{dP} / \mathrm{dt})$, and the marked prolongation of isovolumic contraction time (IVCT) (Fig. 3).

LVSP was brought back toward control values by all treatments [Fig. 3(A)] whereas only the injection of ADSCs adhered to GF-releasing PAMs succeeded in exerting an equivalent restoring effect on $+\mathrm{dP} / \mathrm{dt}$, $-\mathrm{dP} / \mathrm{dt}$, and IVCT changes [Fig. 3(B-D)]. On the contrary, LVEDP, LVRT, and
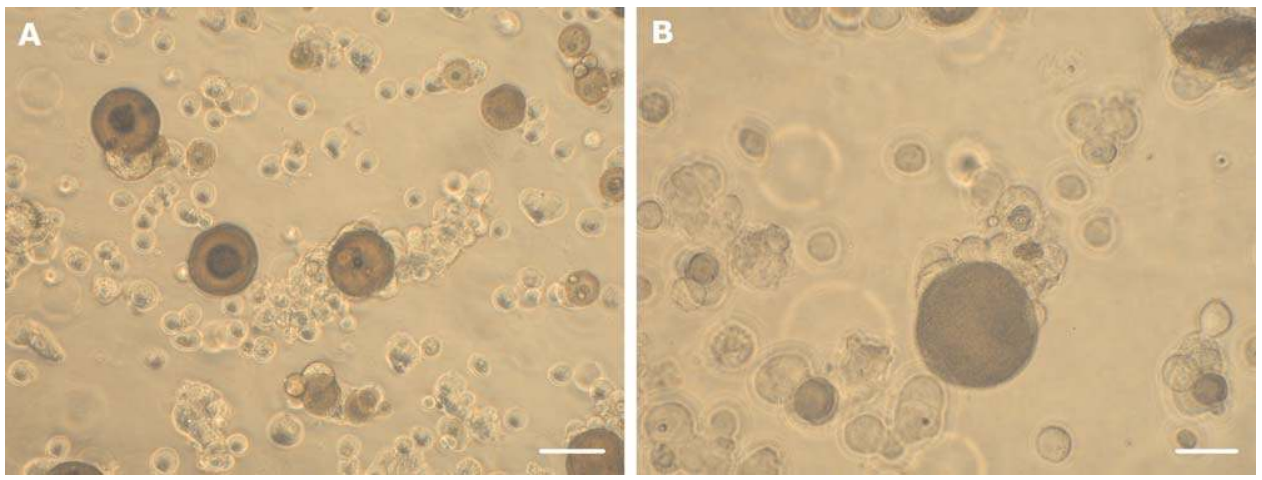

FIGURE 1. In vitro formation of ADSC/PAM complexes. The number of small ADSC/PAM complexes constituted by one only PAM surrounded by a few ADSCs increased after their passage through the 26-G needle of the injection syringe. Magnification: $(A) 200 \times$, bar $=50 \mu m$; $(B) 400 \times$, bar $=25 \mu \mathrm{m}$. [Color figure can be viewed in the online issue, which is available at wileyonlinelibrary.com.] 

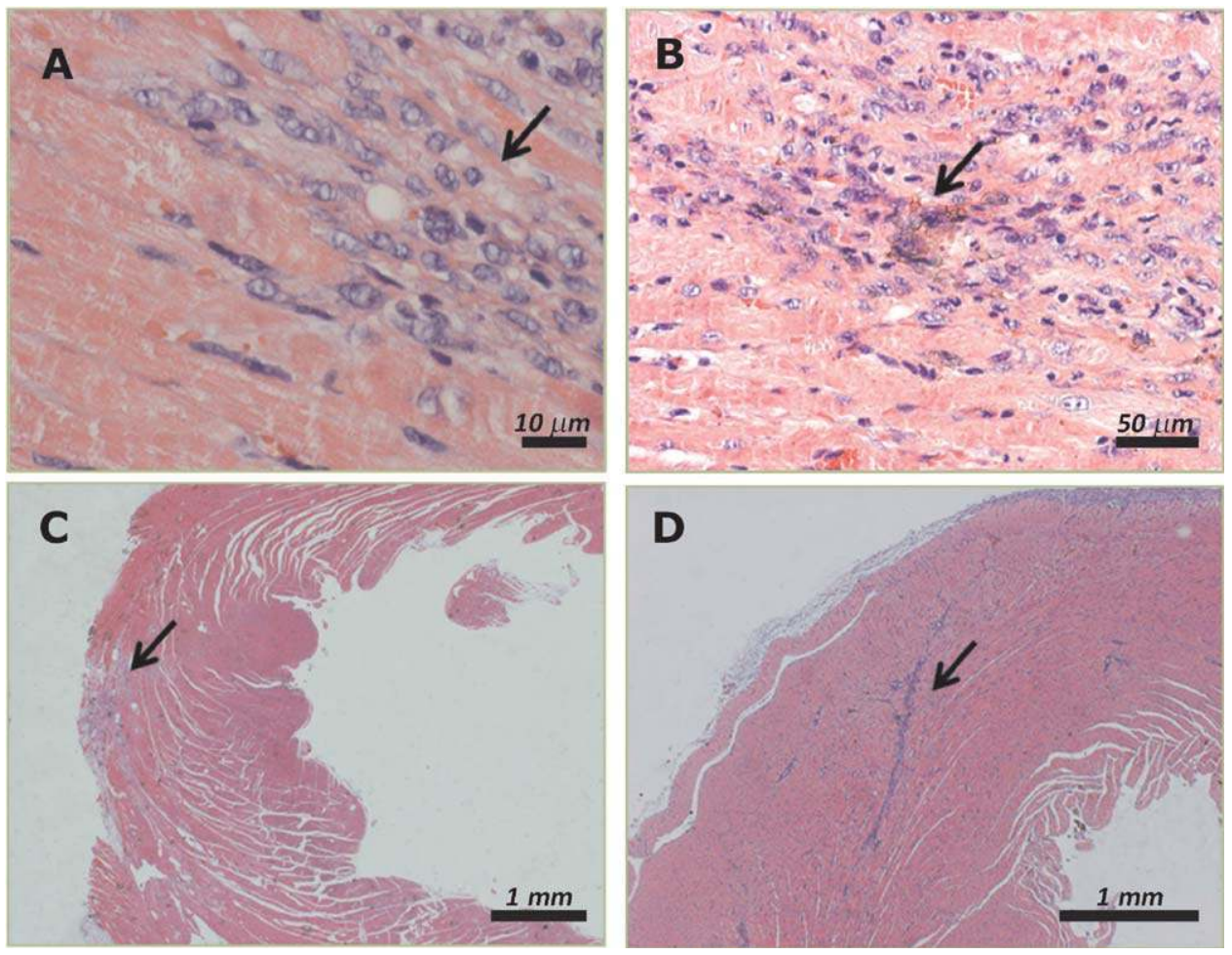

FIGURE 2. Myocardial inflammatory response to PAM injection. Sections of SHAM_V (A, C) and SHAM_PAM (B, D) LV myocardium stained with hematoxylin-eosin, 2 weeks after treatment. The arrows indicate small areas of inflammation with moderate cell infiltration at the injection site (SHAM_V hearts; A-C) and midmyocardial level (SHAM_PAM hearts; B-D). [Color figure can be viewed in the online issue, which is available at wileyonlinelibrary.com.]

A

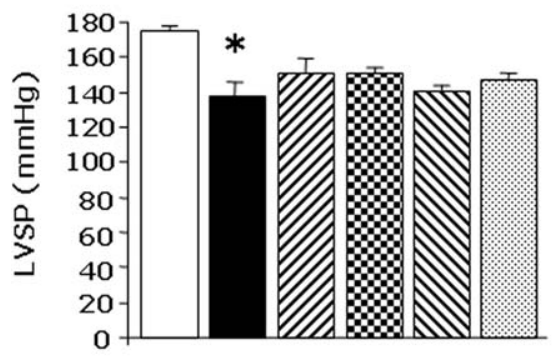

C

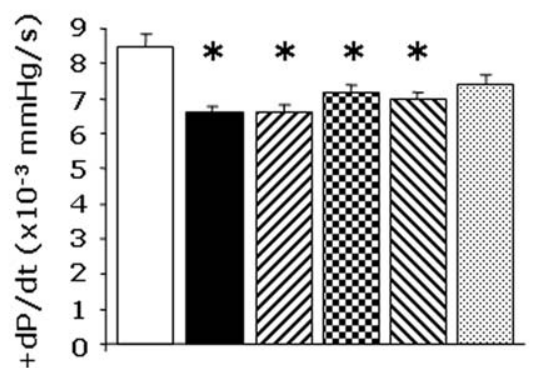

B

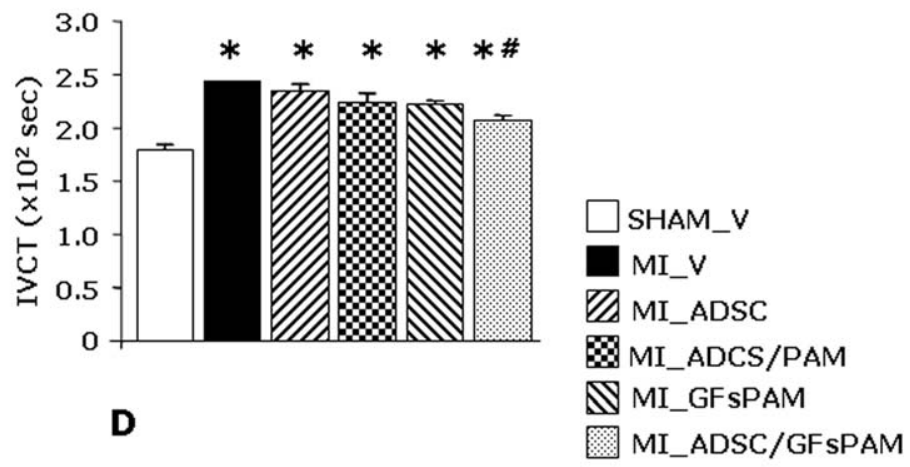

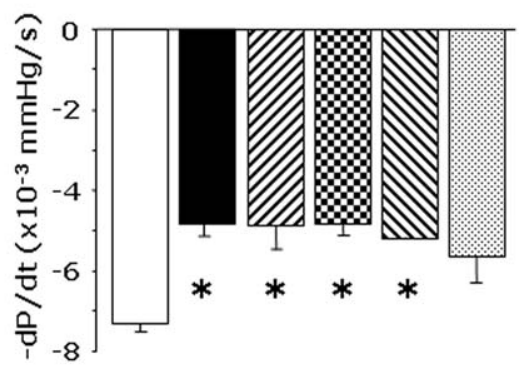

FIGURE 3. Hemodynamic parameters. Mean values \pm SEM of (A) left ventricular systolic pressure (LVSP), (B) isovolumic contraction time (IVCT), (C) maximal rate of $L V$ pressure rise $(+\mathrm{dP} / \mathrm{dt})$, and (D) maximal rate of $\mathrm{LV}$ pressure decline $(-\mathrm{dP} / \mathrm{dt}) .{ }^{*} p<0.05$ vs. SHAM_V; \# $p<0.05 \mathrm{vs}$. MI_V. 
TABLE II. Inducible Ventricular Arrhythmic Events

\begin{tabular}{lcccc}
\hline Groups & $\begin{array}{c}\text { Isolated PVBs (Number } \\
\text { of Episodes) }\end{array}$ & $\begin{array}{c}\text { Consecutive PVBs } \\
\text { (Number of Episodes) }\end{array}$ & $\begin{array}{c}\text { Ventricular Ttachycardia } \\
\text { (Number of Episodes) }\end{array}$ & $\begin{array}{c}\text { Ventricular Tachycardia } \\
\text { (Duration, s) }\end{array}$ \\
\hline SHAM_V & $0-12$ & $0-2$ & $0-3$ & $0.5-3$ \\
MI_V & $0-13$ & $0-2$ & $0-7$ & $0.5-1$ \\
MI_ADSC & $1-11$ & $0-3$ & $0-2$ & $0.5-3$ \\
MI_ADSC/PAM & $0-8$ & $0-6$ & $0-6$ & $0.5-180$ \\
MI_GFsPAM & $0-12$ & $0-6$ & $0-8$ & $0.5-3$ \\
MI_ASC/GFsPAM & $0-12$ & $0-2$ & $0-16$ & $0.5-480$ \\
\hline
\end{tabular}

Ranges of number (first three columns) and duration (last column) of inducible ventricular arrhythmic events. PVBs: Premature ventricular beats (isolated or salvos).

EJT had similar values in the various animal groups (Supporting Information Table S1). Altogether, these findings might suggest a beneficial effect of ADSC/GFsPAM administration on cardiac mechanics, even though the reduced degree of deterioration in the parameters considered (on average 15\% improvement as compared with MI_V) did not ordinarily reach any significant difference from MI_V group.

\section{Inducibility of ventricular arrhythmias after} PAM/ADSC injection

In SHAM_V and MI_V animals most arrhythmic events consisted of premature beats, either isolated or as salvos (2-3 consecutive PVBs), associated with rare episodes of monomorphic and polymorphic ventricular tachycardia, lasting 0.5 to 3 s (Table II). Similarly behaved MI_ADSC and MI_GFsPAM while MI_ADSC/PAM and MI_ADSC/GFsPAM exhibited more complex and prolonged runs of ventricular tachycardia.

To quantify the arrhythmogenic risk, 113 score values were computed (SHAM_V, $n=16$; MI_V, $n=19$; MI_ADSC, $n=22 ; \quad$ MI_ADSC/PAM, $n=26$; MI_GFsPAM, $n=16$; MI_ADSC/GFsPAM, $n=14$ ). The average score value was $0.35 \pm 0.1$ in SHAM_V group and trended to increase in MI_V (by about 25\%) and progressively more in MI_ADSC, MI_ADSC/PAM, MI_GFsPAM, and MI_ADSC/GFsPAM (from 1 to 4 fold) (Fig. 4), yet without any statistically significant difference among groups. Thus, the data globally indicate that both ADSC and PAM injection, with or without GFs, trended to have some unfavorable electrophysiological con-

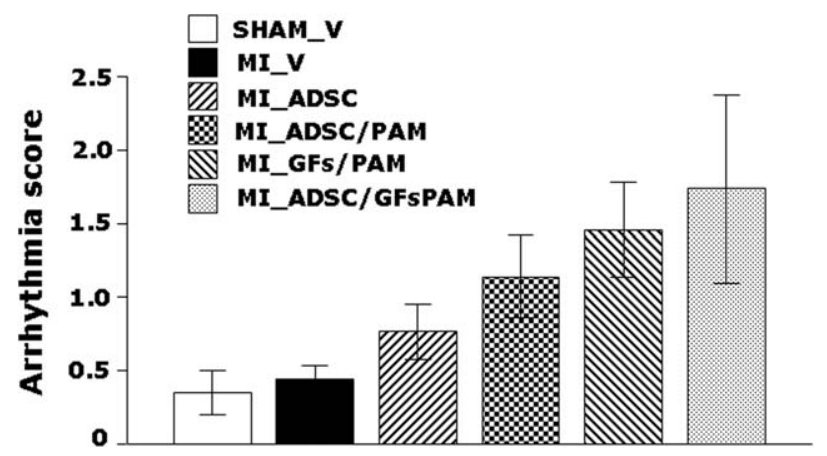

FIGURE 4. Score values of inducible arrhythmias. Mean values \pm SEM of ventricular arrhythmia score. No statistically significant differences among groups were observed. sequences on ventricular electrical stability, requiring additional investigations.

\section{Effects of ADSC/PAM injection on LV remodeling} and infarct size

The recovery toward control values of LV hemodynamics in MI_ADSC/GFsPAM had a structural counterpart. Compared with SHAM_V group, MI_V rats exhibited a marked dilation of LV chamber volume [ $\sim 70 \%$, Fig. $5(\mathrm{~A}) ; p<0.05]$ associated with a moderate increase in LV mass, resulting in a significantly decreased mass-to-chamber volume ratio $[-65 \%$, Fig. 5(B); $p<0.05]$. These anatomical markers of unfavorable remodeling, representing the major determinants of heart failure, were attenuated only in MI_ADSC/GFsPAM group [Fig. 5(A,B)].

The average values of infarct size were similar in all rat hearts equaling $\sim 15 \%$ of the entire LV myocardium (Table III). Animals with low, medium, and large infarct size were represented in every group and the upper and lower limits of the related ranges were comparable (Table III). The gross morphology of myocardial infarcts was not affected by different treatments, too. Likewise, we did not find any difference among groups in LV wall thickness with mean values

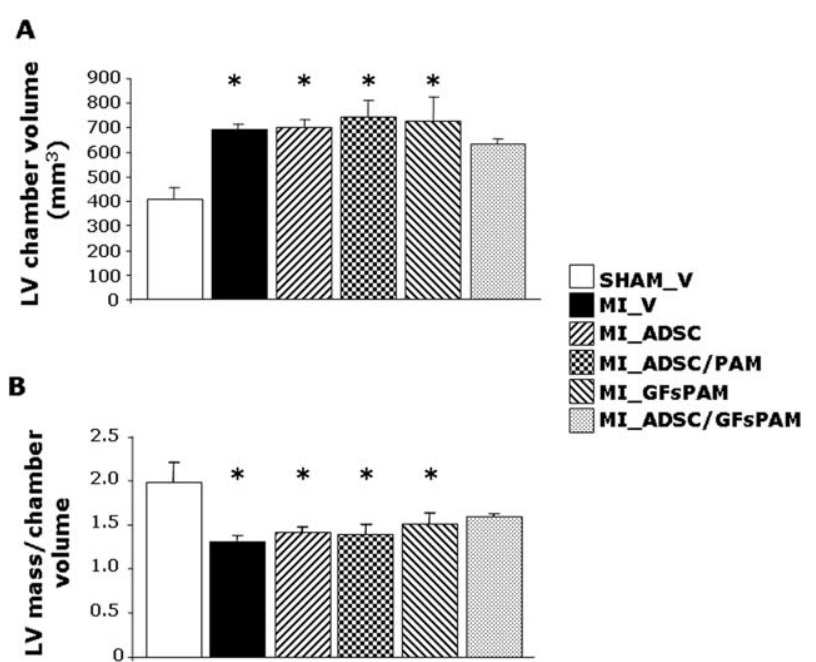

FIGURE 5. Left ventricular remodeling and gross morphometry of the infarcted heart. Mean values \pm SEM of left ventricular chamber volume (A) and LV mass to chamber volume ratio (B), in the different experimental groups. ${ }^{*} p<0.05$ vs. SHAM V. 
TABLE III. Infarct Size

\begin{tabular}{|c|c|c|c|c|c|}
\hline Groups & $\begin{array}{l}\% \text { of Total LV } \\
\text { Myocardium } \\
\text { (Mean) }\end{array}$ & $\begin{array}{l}\% \text { of Total LV } \\
\text { Myocardium } \\
\text { (Range) }\end{array}$ & $\begin{array}{c}\% \text { Equatorial Slice } \\
\text { (Range) }\end{array}$ & $\begin{array}{c}\text { \% Apical Slice } \\
\text { (Range) }\end{array}$ & $\begin{array}{l}\% \text { Basal Slice } \\
\text { (Range) }\end{array}$ \\
\hline $\mathrm{MI} \mathrm{V}(n=6)$ & $12.94 \pm 2.99$ & $6.60-23.77$ & $5.74-30.26$ & $10.19-34.22$ & $6.43-12.55$ \\
\hline MI_ADSC $(n=8)$ & $16.75 \pm 2.81$ & $6.21-27.52$ & $8.94-23.12$ & $5.69-32.80$ & $1.33-32.30$ \\
\hline MI_ADSC/PAM $(n=7)$ & $18.00 \pm 2.77$ & $7.76-31.36$ & $5.89-42.32$ & $15.34-36.65$ & $2.49-10.61$ \\
\hline MI_GFsPAM $(n=6)$ & $10.68 \pm 2.77$ & $4.36-17.92$ & 7.98-16.50 & $5.70-24.53$ & $4.13-13.30$ \\
\hline MI_ADSC/GFsPAM $(n=6)$ & $10.30 \pm 1.68$ & $3.81-12.85$ & $8.02-16.54$ & $2.96-20.89$ & $5.61-20.08$ \\
\hline
\end{tabular}

Mean values \pm SEM (first column) and ranges (2nd-5th columns) of infarct size measured in the entire LV myocardium, and the equatorial, apical and basal slices, in the five experimental groups. No statistically significant differences among groups were observed.

ranging between $1.6 \mathrm{~mm}$ (MI-V group) and $1.9 \mathrm{~mm}$ (MI_GFsPAM).

\section{Vessel density in the infarct area}

Blood vessels were identified as luminal profiles labeled by one or more $\mathrm{vWF}^{+}$cells (Fig. 6).
The overall vascular density (capillaries + vessels of medium size) was reduced as a consequence of MI, irrespective of the treatment. In particular, capillary density, which largely overcomes the density of vessels of medium size, was reduced by about $50 \%$ and no treatment was able to revert these changes (Fig. 6, left bar-graph). On the
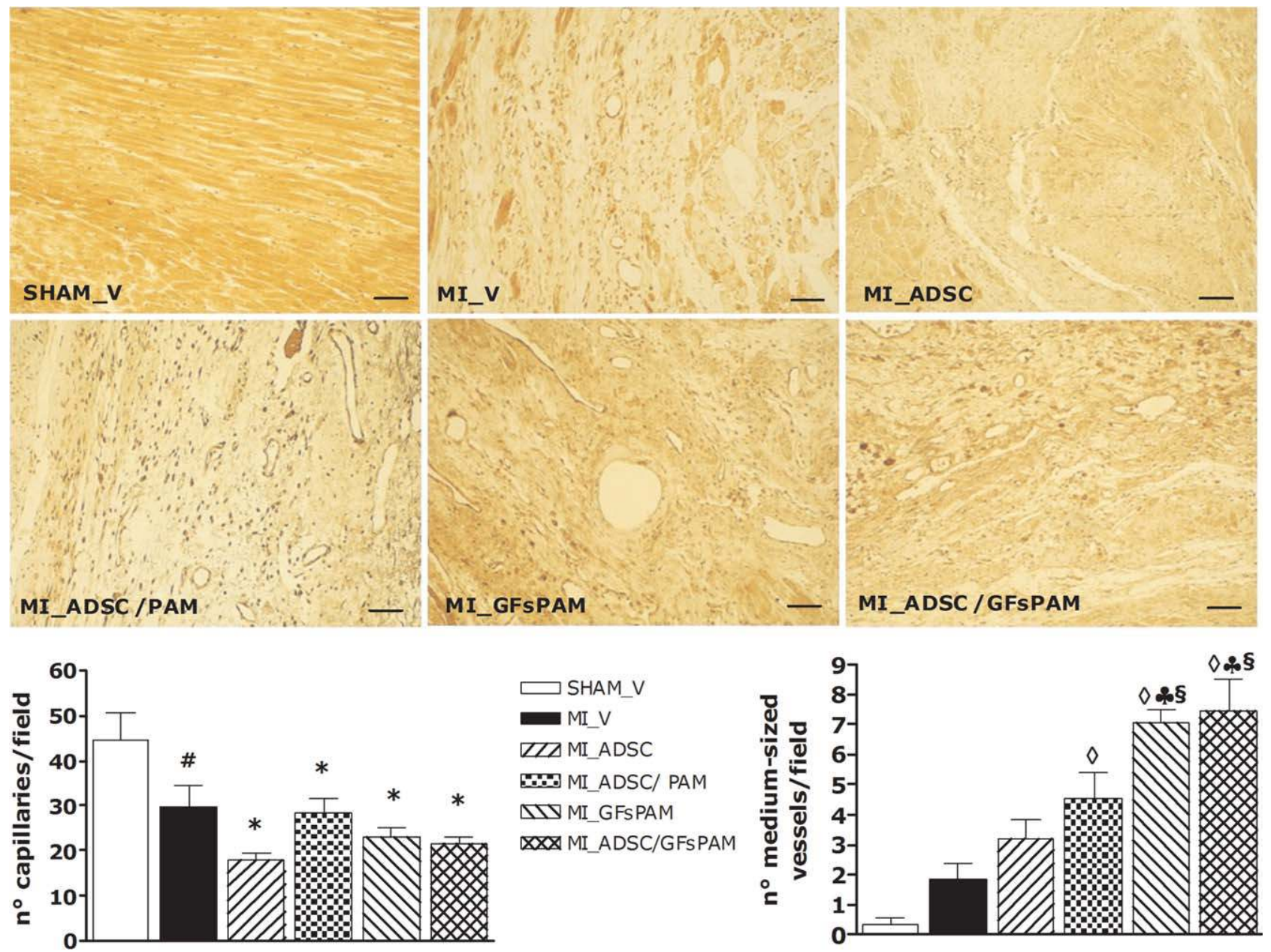

FIGURE 6. Effect of different combination of ADSCs, PAMs, and GFs on vascularization of the infarcted area. Representative micrographs showing blood vessels identified in the infarcted regions as luminal profiles labeled by $v W F$ (magnification $200 \times$, bar $=50 \mu \mathrm{m}$ ). No significant difference on capillary density (left bar-graph) was observed among untreated and treated MI animals, but it was reduced with respect to SHAM V. ${ }^{*} p<0.05$ and $\# p=0.08$ vs. SHAM_V. On the contrary, the amount of vessels with size $>20 \mu m$ (right bar-graph) significantly increased in all groups injected with PAM complexes as compared with SHAM V and the effect was potentiated by GF adjunct (larger values in MI GFsPAM and MI_ADSC/GFsPAM than MI_V and MI_ADSCs). $\diamond p<0.01$ vs. SHAM_V; $\$ p<0.01$ vs. MI_ADSC; $\$ p<0.01$ vs. MI_V. [Color figure can be viewed in the online issue, which is available at wileyonlinelibrary.com.] 


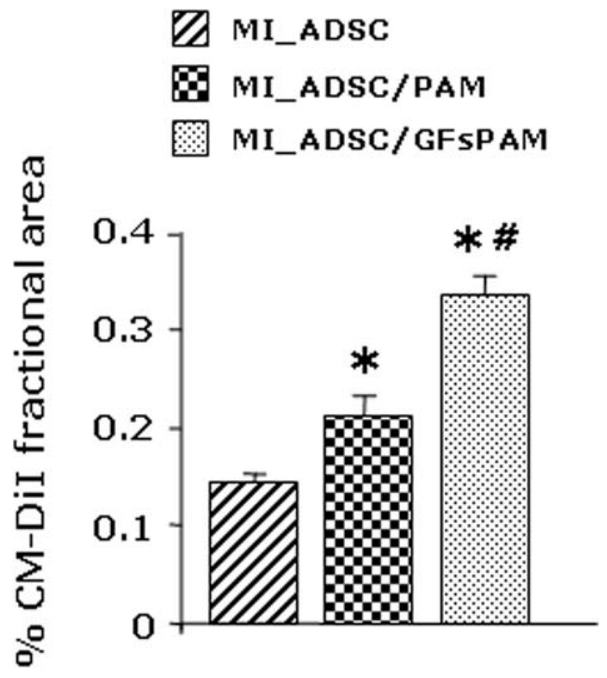

FIGURE 7. Homing of ADSCs in the infarcted heart. The quantification of Dil ${ }^{\text {pos }}$ fractional area indicates that cell homing in the infarcted rat hearts was improved by PAMs and was further enhanced by GFreleasing PAMs. ${ }^{*} p<0.05$ vs. MI_ADSC, $\# p<0.05$ vs. MI ADSC/PAM.

contrary, the amount of medium-sized vessels was significantly enhanced in both MI_GFsPAM and MI_ADSC/GFsPAM with respect to SHAM_V, MI_V, and MI_ADSC (Fig. 6, right bar-graph).

\section{ADSC homing in the infarct area}

The presence of CM-DiI labeled ADSCs on unstained serial sections documented homing to the infarcted $\mathrm{LV}$ of the injected cells (Supporting Information Fig. S3).

Two weeks after cell injection, ADSC engraftment to the infarcted hearts was improved when cells were conveyed by empty PAMs [Supporting Information Fig. S3(A,B)]. Homing within the infarcted myocardium further increased when the rats were treated with ADSCs and GF-releasing PAMs [Supporting Information Fig. S3(C)]. ADSCs were mostly clustered in the (peri)-infarct area but also distributed in the infarcted portion. FISH analysis proved the human origin of homed ADSCs by the presence of human sex chromosomes in cells that corresponded to CM-Dil signals detected in the infarcted myocardium [Supporting Information Fig. S3(D,E)]. These findings were confirmed by quantitative analysis documenting a statistically significant increase in ADSCs homing in groups in which cells were injected with PAMs (Fig. 7).

\section{DISCUSSION}

The present study demonstrates that in a rat model of chronic MI the local injection of human ADSCs conveyed by microspheres continuously releasing HGF and IGF-1, at two weeks after treatment can result in cell engraftment and initial mending of the infarcted area larger than any other combination of growth factors and PAM.

\section{ADSC engraftment}

Cell retention after injection represents a major drawback in cell therapy because approximately $90 \%$ of cells are lost to the circulation or leaked out of the injection site. ${ }^{31}$ Moreover, most of the retained cells die within the first week due to ischaemia, anoikis, and inflammation-related factors. $^{32}$ A favorably action of PAM complexes on promoting homing of the transplanted cells was actually documented by the finding that the number of ADSCs in infarcted area, when coinjected with GF-releasing PAMs, increased by twofolds with respect to ADSCs injected without supporting microparticles. Two different methods were employed to detect ADSC and to confirm the human origin of injected cells, that is, pre-labeling with CM-DiI to track the cell distribution within the infarcted myocardium and FISH analysis of human $\mathrm{X}$ and $\mathrm{Y}$ chromosomes. CM-DiI label is well retained in the cells throughout several mitotic divisions and cell-to-cell contact does not allow dye diffusion. This characteristics promotes CM-DiI as a good dye to be used also to study cell biocompatibility in tissue engineering. ${ }^{33}$ FISH analysis is a standardized method to confirm human origin of injected cell. ${ }^{34}$ Additionally, DAPI staining of the DNA documented individual preserved nuclei carrying human Y chromosome excluding phagocytic phenomena by macrophages and further reinforcing the presence of engrafted living cells.

The microspheres used in the present study can be considered as useful carriers to improve ADSC engraftment for several reasons. First, $\alpha 5 \beta 1$ and $\alpha \mathrm{V} \beta 3$ integrins of ADSCs establish linkages with RGD (Arg-Gly-Asp) sequences of FN that improve cell attachment ${ }^{35}$ and viability, ${ }^{36}$ especially when ADSCs are exposed to apoptotic conditions ${ }^{37}$ such those encountered in the (peri)-infarct area. In addition, the second component of PAM coating, PDL, alters the surface charge to net positive values that improve cell adhesive properties. ${ }^{38}$ Furthermore, due to the proneness of ADSCs to quickly aggregate with PAMs (Supporting Information Fig. S2), it is also conceivable that ADSC/PAM complexes of a higher size could early recompose and be better retained just after their injection in the myocardium, thereby reducing the phenomenon of leakage out of the myocardial wall. Consistently, Diaz-Herraez et al. using a chronic model of MI, demonstrated that PAMs covered with collagen/PDL and releasing neuregulin-1 were well retained in the infarcted area at least for 2 weeks after injection. ${ }^{39}$

Another important feature of PAMs as suitable cell scaffold compared to other vehicles, for example, hydrogels, is their superiority to efficiently incorporate and release bioactive factors in a controlled and sustained manner. The better efficacy of PAMs vs. hydrogels is mainly due to the encapsulation procedure that protects the entrapped proteins from degradation through their dehydration and nanoprecipitation. Moreover, releasing time parameters are also finely tunable in PAMs, for instance by modifying PLGA solubility (for example, lactic:glycolic acid ratio) or the composition of precipitation/encapsulation solutions and superficial coating. Indeed, in the present study the GFs released from PAMs led to a further increase in ADSC engraftment compared to the effects elicited by PAMs alone. It is well known that IGF-1 is a pro-survival factor and this is true for ADSCs that naturally express the IGF-1 receptor. ${ }^{40}$ Our in vitro 
study of IGF-1 release profile ${ }^{16}$ showed an initial burst in the first week that presumably could potentiate the prosurvival effect allowing ADSCs to better counteract the impact with the hostile environment. However, it is conceivable that in the following week the lower, but constant, release of biologically active IGF-1 was useful to maintain cell protection as well.

Another interesting point to be underlined is that the motility of ADSCs conveyed by PAMs was stimulated, as shown by their migration from the border zone, that is, the injection point, to the fibrous area. To partially explain this finding, it might be hypothesized that the increased vascularization that followed our treatment had favored ADSC migration by providing a more oxygenated, less dangerous milieu, for their homing.

Other studies emphasized the positive effects on stem cell engraftment due to the presence of IGF-1, although under conditions which differ from our experimental protocol. Wang et al. demonstrated that a single injection of IGF1 plus HGF increased the homing of cardiac Sca- $1^{+} / \mathrm{CD}^{-} 1^{-}$ cells transplanted in an acute model of mouse MI. ${ }^{41}$ Enoki et al. showed an increased engraftment of bone marrowderived mesenchymal stem cells in chronically infarcted myocardium due to the simultaneous injection of IGF-1, up to 3 days from cell transplantation. ${ }^{42}$ It is noteworthy that the improved retention of ADSCs in our study was prolonged for a longer time and that this result could be attributable to the sustained release of IGF-1.

Finally, we suppose that the poor inflammatory reaction that followed PAM injection did not hamper cell retention since the percent of engrafted ADSCs carried by the microspheres was significantly higher than that referred to ADSCs transplanted alone.

\section{Angiogenic effects}

Our study documented an increased vascularization of the infarcted area, attributable to GFs rather than ADSCs. Indeed, the density of medium-sized blood vessels, that is, arterioles, venules, and/or immature conduits, was enhanced by about four times in the infarcted region using GF-releasing PAMs alone or with ADSCs, as compared with vehicle. Therefore, despite the ability of ADSCs to stimulate vessel outgrowth, ${ }^{43,44}$ the similar outcome in MI_GFsPAM and MI_ADSC/GFsPAM rat hearts ruled out any synergistic effect between ADSCs and GF-releasing PAMs, indicating that the cells were unable to further enhance the angiogenic effect of HGF released by PAM. In line with this finding, ADSCs alone or conveyed by empty PAMs failed to significantly raise the total amount of medium-sized vessels in comparison with vehicle. Importantly, by the same rat model of $\mathrm{MI}^{22}$ we recently demonstrated that a single injection of GFs also increased vascular density but to a lesser extent than GF-releasing PAMs, suggesting again that a sustained release can prolong (and hence improve) the effects of these factors.

In contrast, neither ADSCs nor GF-releasing PAMs, taken alone or in combination, were capable to increase the number of capillaries in the (peri)-infarct area. Comparable results were previously obtained by our group, documenting that the better perfusion of the infarct area following local injection of mesenchymal stem cells was related to the increased density of large vessels rather than capillaries. ${ }^{45}$ In accordance with these findings, published data indicated that the number of capillaries could even decrease after mesenchymal stem cell transplantation in spite of improved myocardial perfusion. ${ }^{46}$ Noteworthy, angiogenic factors may stimulate capillary arterialization, giving rise to mediumlarge vessels at the expense of smaller vessels. ${ }^{47}$ Finally, another possible explanation of the inability of ADSCs to increase capillary density in the chronically infarcted area might be provided by the absence of the inflammatory reaction that immediately follows an acute MI, representing a striking trigger of angiogenesis. However, it is unlikely that the slight inflammatory response to PAM injection contributed to increase vascularization, as the amount and morphology of tissue damage did not differ from that induced by vehicle, at 2 weeks after treatment.

\section{Mechanical function and structural remodeling}

The results of this study demonstrate that only ADSC/ GFsPAM treatment succeeded in reducing the deterioration of cardiac hemodynamics and LV structural remodeling of the infarcted heart, suggesting a key role of sustained GF delivery in favoring ADSC reparative capacity. These findings are in accordance with data from previous reports in which the two GFs have been used either separately or in combination. ${ }^{20-22,48,49}$ Thus, it was shown that intramyocardial injection of HGF-naked-DNA plasmid in dogs with heart failure induced by intracoronary microembolization attenuate abnormalities in the expression of sarcoplasmic reticulum $\mathrm{Ca}^{2+}$-cycling proteins, improving regional and global $\mathrm{LV}$ function and preventing progressive LV structural alterations. ${ }^{48}$ More recently, in a mouse model of ischemiareperfusion, Khan et al. documented that intravenous delivery of Hoechst-IGF-1 protects from the development of cardiac fibrosis and counteract passive stiffness that follows ischemic injury, improving cardiac function. ${ }^{49}$ Furthermore, recent findings demonstrated a synergistic positive action of the two growth factors when administered in combination, as in this study. ${ }^{20-22}$ Indeed, the coinjection of HGF and IGF1 in experimental models of both acute and chronic MI was shown to improve LV hemodynamic performance and reduce unfavorable LV remodeling. ${ }^{20-22}$

\section{Analysis of proneness to arrhythmias}

The effects of the various treatments on the arrhythmic risk were less definite than those concerning cell engraftment as well as cardiac remodeling and mechanics. Proneness to arrhythmias, as determined by PES/RVP, trended to be higher in animals injected with different combinations of ADSCs, GFs, and PAM than untreated MI, although none of the changes reached the statistical significance. However, the possibility that under specific circumstances these adverse electrophysiological consequences might turn into more severe arrhythmias cannot be ruled out. It is still debated whether local injection of stem cells for mending 
the infarcted heart can provoke derangements in cardiac electrogenesis thereby exacerbating the harmful outcome of post-MI arrhythmic substrate. ${ }^{50,51}$ Yet, preclinical studies have shown that ADSCs possess a full functional range of ion channels even in an early undifferentiated stage. ${ }^{52}$ Following the injection in the border zone and infarct area of mouse hearts, ADSCs developed a cardiac phenotype, incorporated into healthy myocardium surrounding the infarcted region, and formed connexin 43-positive gap junctions between themselves and host cardiomyocytes. ${ }^{53}$ Although additional electrophysiological studies are required to confirm the full differentiation of the injected cells into functional cardiomyocytes, the above properties appear to be crucial for the transplanted cells to engraft without negatively affecting cardiac electrical stability. Concurrently, injection of autologous ADSCs in infarcted porcine myocardium was shown to decrease vulnerability to induction of arrhythmias. ${ }^{54}$ Finally, no malignant arrhythmias were seen in the first clinical trial of adipose-derived regenerative cells in patients with ischemic cardiomyopathy. ${ }^{55}$ These data raise the concern that arrhythmias documented in our experimental setting were not caused by injected cells but rather derived from alterations in the natural spread of excitation in myocardial tissue, arguably linked to unfavorable electrical properties of combined cell-vector structures. Interestingly, the score value of induced arrhythmic events in treated animals was roughly correlated with the complexity of PAM in terms of number of bioactive factors conveyed by the device and hence its size, suggesting that increased proneness to arrhythmias might be dependent on the degree of obstruction to current flow represented by PAM.

\section{PAM biocompatibility}

Several investigators have also indicated that in cell therapy administered via intramyocardial injection there may be a transient, early arrhythmic risk, possibly due to inflammatory reactions or irritative effects, or both. We have verified that PAMs per se did not cause any relevant inflammatory response in the infarcted heart. In fact, despite an increased formation of transient foci during the first week from the injection, the inflammatory lesions became comparable to those provoked by the vehicle just after the second week. We did not attempt to dissociate the relative effects of foreign body reaction to PLGA, immunological reaction to human cells, inflammation due to cell death, and injury created by injection. Notably, the highest number of small inflammatory foci were found at the subepicardial level, suggesting a direct injury induced by the injection. However, one can anticipate that some effects might be arguably related to PLGA action only.

\section{Limitations of the study}

Some limitations of this study are related to the methodological aspects. We investigated the effects of the treatments at 2 weeks after injection, as this time corresponds to the most relevant window of GF release from PAMs. ${ }^{16}$ Moreover, the probability to find the engrafted ADSCs in the infarcted region, representing the main aim of our study, would be lower after longer time periods. Finally, the selected time would enable us to compare our results with those previously obtained in similar experimental setting using a single injection of GFs. ${ }^{22}$ This choice involved that both mechanical function and structural remodeling in the adopted model of chronic MI were expected to be constituted only by initial signs of morpho-functional recovery. Therefore, as a second step, our future research will be focused on the effects of ADSCs and GFs-PAMs after a longer time interval. This would also make it possible to better evaluate both type and degree of engrafted ADSCs and related differentiation into vascular and/or cardiomyocyte phenotypes. ${ }^{56}$

On account of the multifactorial nature of arrhythmogenesis and the erratic occurrence of malignant arrhythmias in subjects with cardiac electrical instability we included in the study all anatomically documented MI, independently of their extension. This might also have concurred in determining the relatively low average values of infarct size and, in turn, providing a partial explanation of the lack of marked differences among treated and untreated MI animals, in accordance with previous investigations. ${ }^{57}$

We are not aware of any report describing cardiac electrical instability in relation to polymeric microsphere dimensions and a comparative analysis is needed to verify whether the tendency to induce arrhythmias decreases by employing lower-sized PAMs. However, it should be taken into consideration that the size of PAM surface is critical for supporting and conveying ADSCs. In addition, published data $^{58}$ indicate that very small PAMs $(<5 \mu \mathrm{m})$ may induce macrophagic responses as they may be phagocytosed.

Finally, upcoming projects should also include groups treated with PAMs or soluble GFs alone to make clear the role that these two variables can play in the mechanisms of myocardial healing and/or regeneration.

\section{CONFLICT OF INTEREST}

All authors have no conflict of interest.

\section{ACKNOWLEDGMENTS}

The authors acknowledge the Technical assistance of Emilia Corradini and Gabriella Becchi.

\section{REFERENCES}

1. Segers V, Lee T. Stem-cell therapy for cardiac disease. Nature 2008;451:937-942.

2. Müller-Ehmsen J, Whittaker $P$, Kloner RA, Dow JS, Sakoda T, Long TI, Laird PW, Kedes L. Survival and development of neonatal rat cardiomyocytes transplanted into adult myocardium. J Mol Cell Cardiol 2002;34:107-116.

3. Wu KH, Mo XM, Han ZC, Zhou B. Stem cell engraftment and survival in the ischemic heart. Ann Thorac Surg 2011;92:1917-1925.

4. Muscari $C$, Bonafè F, Fiumana E, Oranges CM, Pinto V, Caldarera CM, Guarnieri C, Morselli PG. Comparison between stem cells harvested from wet and dry lipoaspirates. Connect Tissue Res 2013;54:34-40.

5. Pasini A, Bonafè F, Govoni M, Guarnieri C, Morselli PG, Sharma HS, Caldarera CM, Muscari C, Giordano E. Epigenetic signature of early cardiac regulatory genes in native human adipose-derived stem cells. Cell Biochem Biophys 2013; 67:255-262.

6. Qayyum AA, Haack-Sørensen M, Mathiasen AB, Jørgensen $E$, Ekblond A, Kastrup J. Adipose-derived mesenchymal stromal 
cells for chronic myocardial ischemia (MyStromalCell trial): Study design. Regen Med 2012;7:421-428.

7. Przybyt E, van Luyn MJ, Harmsen MC. Extracellular matrix components of adipose derived stromal cells promote alignment, organization, and maturation of cardiomyocytes in vitro. J Biomed Mater Res A. Forthcoming. doi:10.1002/jbm.a.35311.

8. Tatard VM, Venier-Julienne MC, Saulnier Prechter E, Benoit JP Menei P, Montero-Menei CN. Pharmacologically active microcarriers: A tool for cell therapy. Biomaterials 2005;26:3727-3737.

9. Penna C, Perrelli MG, Karam JP, Angotti C, Muscari C, MonteroMenei CN, Pagliaro P. Pharmacologically active microcarriers influence VEGF-a effects on mesenchymal stem cell survival. J Cell Mol Med 2013;17:192-204.

10. Musilli C, Karam JP, Paccosi S, Muscari C, Mugelli A, MonteroMenei CN, Parenti A. Pharmacologically active microcarriers for endothelial progenitor cell support and survival. Eur J Pharm Biopharm 2012;81:609-616.

11. Garbayo E, Raval AP, Curtis KM, Della-Morte D, Gomez LA, D'Ippolito G, Reiner T, Perez-Stable C, Howard GA, Perez-Pinzon MA, Montero-Menei CN, Schiller PC. Neuroprotective properties of marrow-isolated adult multilineage-inducible cells in rat hippocampus following global cerebral ischemia are enhanced when complexed to biomimetic microcarriers. J Neurochem 2011;119: 972-988.

12. Delcroix GJ, Garbayo E, Sindji L, Thomas O, Vanpouille-Box C, Schiller PC, Montero-Menei CN. The therapeutic potential of human multipotent mesenchymal stromal cells combined with pharmacologically active microcarriers transplanted in hemiparkinsonian rats. Biomaterials 2011;32:1560-1573.

13. Morille M, Van-Thanh T, Garric X, Cayon J, Coudane J, Noël D, Venier-Julienne MC, Montero-Menei CN. New PLGA-P188-PLGA matrix enhances TGF- $\beta 3$ release from pharmacologically active microcarriers and promotes chondrogenesis of mesenchymal stem cells. J Control Release 2013;170:99-110.

14. Giteau A, Venier-Julienne MC, Marchal S, Courthaudon JL, Sergent M, Montero-Menei C, Verdier JM, Benoit JP. Reversible protein precipitation to ensure stability during encapsulation within PLGA microspheres. Eur J Pharm Biopharm 2008;70:127136.

15. Tran VT, Karam JP, Garric X, Coudane J, Benoit JP, MonteroMenei CN, Venier-Julienne MC. Protein-loaded PLGA-PEG-PLGA microspheres: A tool for cell therapy. Eur J Pharm Sci 2012;45: 128-137.

16. Karam JP, Muscari C, Sindji L, Bastiat G, Bonafè F, VenierJulienne MC, Montero-Menei NC. Pharmacologically active microcarriers associated with thermosensitive hydrogel as a growth factor releasing biomimetic 3D scaffold for cardiac tissue-engineering. J Control Release 2014;192:82-94.

17. Davis ME, Hsieh PC, Takahashi $T$, Song $Q$, Zhang $S$, Kamm RD, Grodzinsky AJ, Anversa P, Lee RT. Local myocardial insulin-like growth factor 1 (IGF-1) delivery with biotinylated peptide nanofibers improves cell therapy for myocardial infarction. Proc Natl Acad Sci USA 2006;103:8155-8160.

18. Chen $\mathrm{XH}$, Minatoguchi $\mathrm{S}$, Kosai $\mathrm{K}$, Yuge $\mathrm{K}$, Takahashi T, Arai $\mathrm{M}$, Wang $N$, Misao $Y$, Lu C, Onogi $H$, Kobayashi $H$, Yasuda S, Ezaki M, Ushikoshi H, Takemura G, Fujiwara T, Fujiwara H. In vivo hepatocyte growth factor gene transfer reduces myocardial ischemia-reperfusion injury through its multiple actions. J Card Fail 2007;13:874-883.

19. Wang $Q D$, Sjöquist PO. Myocardial regeneration with stem cells: Pharmacological possibilities for efficacy enhancement. Pharmacol Res 2006;53:331-340.

20. Urbanek K, Rota $M$, Cascapera S, Bearzi C, Nascimbene A, De Angelis A, Hosoda T, Chimenti S, Baker M, Limana F, Nurzynska D, Torella D, Rotatori F, Rastaldo R, Musso E, Quaini F, Leri A, Kajstura J, Anversa P. Cardiac stem cells possess growth factorreceptor systems that after activation regenerate the infarcted myocardium, improving ventricular function and long-term survival. Circ Res 2005:97:663-673.

21. Ellison GM, Torella D, Dellegrottaglie $S$, Perez-Martinez $C$, Perez de Prado A, Vicinanza C, Purushothaman S, Galuppo V, laconetti C, Waring CD, Smith A, Torella M, Cuellas Ramon C, GonzaloOrden JM, Agosti V, Indolfi C, Galiñanes M, Fernandez-Vazquez F,
Nadal-Ginard B. Endogenous cardiac stem cell activation by insulin-like growth factor-1/hepatocyte growth factor intracoronary injection fosters survival and regeneration of the infarcted pig heart. J Am Coll Cardiol 2011;58:977-986.

22. Bocchi L, Savi M, Graiani G, Rossi S, Agnetti A, Stillitano F, Lagrasta C, Baruffi S, Berni R, Frati C, Vassalle M, Squarcia U, Cerbai E, Macchi E, Stilli D, Quaini F, Musso E. Growth factorinduced mobilization of cardiac progenitor cells reduces the risk of arrhythmias, in a rat model of chronic myocardial infarction. PLoS One 2011;6:e17750

23. Paillard-Giteau A, Tran VT, Thomas Garric X, Coudane J, Marchal S, Chourpa I, Benoît JP, Montero-Menei CN, Venier-Julienne MC. Effect of various additives and polymers on lysozyme release from PLGA microspheres prepared by an s/o/w emulsion technique. Eur J Pharm Biopharm 2010;75:128-136.

24. Zuk PA, Zhu M, Ashjian P, De Ugarte DA, Huang JI, Mizuno H, Alfonso ZC, Fraser JK, Benhaim P, Hedrick MH. Human adipose tissue is a source of multipotent stem cells. Mol Biol Cell 2002;13: 4279-4295.

25. Walker MJ, Curtis MJ, Hearse DJ, Campbell RW, Janse MJ, Yellon DM, Cobbe SM Coker SJ, Harness JB, Harron DW Higgins AJ, Julian DG, Lab MJ, Manning S, Northover BJ, Parratt JR, Riemersma RA Riva E, Russell DC, Sheridan DJ, Winslow E, Woodward B. The lambeth conventions: Guidelines for the study of arrhythmias in ischaemia infarction, and reperfusion. Cardiovasc Res 1988;22:447-455.

26. Curtis MJ, Walker MJ. Quantification of arrhythmias using scoring systems: An examination of seven scores in an in vivo model of regional myocardial ischaemia. Cardiovasc Res 1988;22:656665.

27. Dodge HT, Baxley WA. Left ventricular volume and mass and their significance in heart disease. Am J Cardiol 1969;23:528-537.

28. Quaini $F$, Urbanek K, Beltrami AP, Finato N, Beltrami CA, NadalGinard B, Kajstura J, Leri A, Anversa P. Chimerism of the transplanted heart. N Engl J Med 2002;346:5-15.

29. Bandopadhyay R, Orte C, Lawrenson JG, Reid AR, De Silva S, Allt G. Contractile proteins in pericytes at the blood-brain and bloodretinal barriers. J Neurocytol 2001;30:35-44.

30. Huang SJ, Fu RH, Shyu WC, Liu SP, Jong GP, Chiu YW, Wu HS, Tsou YA, Cheng CW, Lin SZ. Adipose-derived stem cells: Isolation, characterization, and differentiation potential. Cell Transplant 2013:22:701-709.

31. Leor J, Aboulafia-Etzion S, Dar A, Barbash IM, Battler A, Granot $Y$, Cohen S. Bioengineered cardiac grafts: A new approach to repair the infracted myocardium? Circulation 2000;102:III56-III61.

32. Wang $\mathrm{H}$, Zhou J, Liu Z, Wang C. Injectable cardiac tissue engineering for the treatment of myocardial infarction. J Cell Mol Med 2010;14:1044-1055.

33. Rai R, Tallawi M, Barbani N, Frati C, Madeddu D, Cavalli S, Graiani G, Quaini F, Roether JA, Schubert DW, Rosellini E, Boccaccini AR. Biomimetic poly(glycerol sebacate) (PGS) membranes for cardiac patch application. Mater Sci Eng C Mater Biol Appl 2013;33:3677-3687.

34. Rossini A, Frati C, Lagrasta C, Graiani G, Scopece A, Cavalli S, Musso $E$, Baccarin M, Di Segni M, Fagnoni F, Germani A, Quaini E, Mayr M, Xu Q, Barbuti A, DiFrancesco D, Pompilio G, Quaini F, Gaetano C, Capogrossi MC. Human cardiac and bone marrow stromal cells exhibit distinctive properties related to their origin. Cardiovasc Res 2011;89:650-660.

35. Lam MT, Longaker MT. Comparison of several attachment methods for human iPS, embryonic and adipose-derived stem cells for tissue engineering. J Tissue Eng Regen Med 2012;6:s80-s86.

36. Michel JB. Anoikis in the cardiovascular system: Known and unknown extracellular mediators. Arterioscler Thromb Vasc Biol 2003;23:2146-2154.

37. di Summa PG, Kalbermatten DF, Raffoul W, Terenghi G, Kingham PJ. Extracellular matrix molecules enhance the neurotrophic effect of schwann cell-like differentiated adipose-derived stem cells and increase cell survival under stress conditions. Tissue Eng Part A 2013;19:368-379.

38. MCKeehan WL. Methods for preparation of media, supplements, and substrata for serum-free animal cell culture. New York: AR Liss; 1984 
39. Díaz-Herráez $P$, Garbayo $E$, Simón-Yarza T, Formiga FR, Prosper F, Blanco-Prieto MJ. Adipose-derived stem cells combined with neuregulin-1 delivery systems for heart tissue engineering. Eur $\mathrm{J}$ Pharm Biopharm 2013;85:143-150.

40. Scioli MG, Cervelli V, Arcuri G, Gentile P, Doldo E, Bielli A Bonanno $E$, Orlandi $A$. High insulin-induced down-regulation of Erk-1/IGF-1R/FGFR-1 signaling is required for oxidative stressmediated apoptosis of adipose-derived stem cells. J Cell Physiol 2014;229:2077-2087.

41. Wang $X, \mathrm{Li} \mathrm{Q}, \mathrm{Hu} \mathrm{Q}$, Suntharalingam $\mathrm{P}$, From $\mathrm{AH}$, Zhang J. Intramyocardial injection of both growth factors and heart derived Sca-1+/CD31- cells attenuates post-MI LV remodeling more than does cell transplantation alone: Neither intervention enhances functionally significant cardiomyocyte regeneration. PLoS One 2014;9:e95247

42. Enoki C, Otani H, Sato D, Okada T, Hattori R, Imamura H. Enhanced mesenchymal cell engraftment by IGF-1 improves left ventricular function in rats undergoing myocardial infarction. Int J Cardiol 2010;138:9-18.

43. Valina C, Pinkernell K, Song YH, Bai X, Sadat S, Campeau RJ, Le Jemtel TH, Alt E. Intracoronary administration of autologous adipose tissue-derived stem cells improves left ventricular function, perfusion, and remodelling after acute myocardial infarction. Eur Heart J 2007;28:2667-2677.

44. Muscari C, Giordano E, Bonafè F, Govoni M, Guarnieri C. Strategies affording prevascularized cell-based constructs for myocardial tissue engineering. Stem Cells Int 2014;2014:434169

45. Muscari C, Bonafè F, Martin-Suarez S, Valgimigli S, Valente $S$, Fiumana E, Fiorelli F, Rubini G, Guarnieri C, Caldarera CM Capitani O, Arpesella G, Pasquinelli G. Restored perfusion and reduced inflammation in the infarcted heart after grafting stem cells with a hyaluronan-based scaffold. J Cell Mol Med 2013;17: 518-530.

46. Schuleri $\mathrm{KH}$, Amado LC, Boyle AJ, Centola M, Saliaris AP Gutman MR, Hatzistergos KE, Oskouei BN, Zimmet JM, Young RG, Heldman AW, Lardo AC, Hare JM. Early improvement in cardiac tissue perfusion due to mesenchymal stem cells. Am J Physiol Heart Circ Physiol 2008;294:H2002-H2011.

47. Rissanen TT, Korpisalo P, Markkanen JE, Liimatainen T, Ordén MR, Kholová I, de Goede A, Heikura T, Gröhn OH, Ylä-Herttuala
S. Blood flow remodels growing vasculature during vascular endothelial growth factor gene therapy and determines between capillary arterialization and sprouting angiogenesis. Circulation 2005;112:3937-4396.

48. Rastogi S, Guerrero M, Wang M, Ilsar I, Sabbah MS, Gupta RC, Sabbah HN. Myocardial transfection with naked DNA plasmid encoding hepatocyte growth factor prevents the progression of heart failure in dogs. Am J Physiol Heart Circ Physiol 2011;300: H1501-H1509.

49. Khan RS, Martinez MD, Sy JC, Che PL, Brown ME, Cabigas EB, Dasari M, Murthy N, Davis ME. Targeting extracellular DNA to deliver IGF-1 to the injured heart. Sci Rep 2014;4:4257

50. Macia E, Boyden PA. Stem cell therapy is proarrhythmic. Circulation 2009;119:1814-1823.

51. Ly HQ, Nattel S. Stem cells are not proarrhythmic: Letting the genie out of the bottle. Circulation 2009;119:1824-1831.

52. Zuk P. Adipose-derived stem cells in tissue regeneration: $A$ review," ISRN Stem Cells 2013;2013:ID 713959.

53. Bai $X$, Yan $Y$, Song $Y H$, Seidensticker M, Rabinovich B, Metzele $R$, Bankson JA, Vykoukal D, Alt E. Both cultured and freshly isolated adipose tissue-derived stem cells enhance cardiac function after acute myocardial infarction. Eur Heart J 2010;31:489-501.

54. Meliga E, Strem BM, Duckers HJ, Serruys PW. Adipose-derived cells. Cell Transplant 2007;16:963-970.

55. Perin EC, Sanz-Ruiz R, Sánchez PL, Lasso J, Pérez-Cano $R$, Alonso-Farto JC, Pérez-David E, Fernández-Santos ME, Serruys PW, Duckers HJ, Kastrup J, Chamuleau S, Zheng Y, Silva GV Willerson JT, Fernández-Avilés F. Adipose-derived regenerative cells in patients with ischemic cardiomyopathy: The PRECISE trial. Am Heart J 2014;168:88-95.

56. Karam JP, Bonafè F, Sindji L, Muscari C, Montero-Menei CN. Adipose-derived stem cell adhesion on laminin-coated microcarriers improves commitment toward the cardiomyogenic lineage. J Biomed Mater Res A. Forthcoming. doi:10.1002/jbm.a.35304.

57. Bayes-Genis A, Gálvez-Montón C, Prat-Vidal C, Soler-Botija C. Cardiac adipose tissue: A new frontier for cardiac regeneration? Int J Cardiol 2013;167:22-25.

58. Champion JA, Walker A, Mitragotri S. Role of particle size in phagocytosis of polymeric microspheres. Pharm Res 2008;25: 1815-1821. 